\title{
Studying Individual Psi Experiences ${ }^{1,2}$
}

\author{
Gertrude R. Schmeidler \\ City University of New York
}

\begin{abstract}
To understand psi, we must study it at multiple levels of analysis. We need a sociology of psi, examining its patterns in different cultures and social groups; life history data so that we can find causes for changes in an individual's psi ability; research on the conditions which affect ESP and PK in short periods like a single experimental session; and we also need careful examination of the individual psi experience. The latter is particularly difficult for several reasons: (1) The duration of the individual experience is unknown (a review of spontaneous cases suggests it may last for the briefest reportable flash, perhaps a tenth or hundredth of a second, or may continue for several minutes); (2) any one hit in an ESP experiment may be due to chance, not to psi; (3) psi often gives imperfect information (only partially correct or systematically misdirected); and (4) psi is not ordinarily under conscious control.

Suggestions for coping with these difficulties are examined. An ongoing experiment is described which investigates EEG changes related to the individual psi experience and, at the same time, attempts to teach subjects to identify and control psi success.
\end{abstract}

Our mental experiences flow in a stream of consciousness, as William James told us long ago; and as Freud told us only a little later, under this stream there are deeper flowing unconscious currents which sometimes rise to mingle with the conscious ones. All of these are a part of the ongoing flow of brain and other body processes; and of course these affect and are affected by the flow of events that make up our universe. A major research problem in parapsychology and indeed in any science is how best to try to understand their causal relations, and finally to try to predict and even control processes which are often so evanescent that they have merged into other processes by the time we begin to respond to them.

Almost the same problem comes up if we try to describe a movie or a television show. The simple, natural way is to state the theme or the plot outline; but this is such a vague, over-generalized summary that it loses the significant details. It is not good enough. At the other extreme we could isolate one frame-one static picture- and stay with it until it is fully described. This gives us precision; but even if we did it for each frame, it would leave out the most meaningful aspect of what we are talking about, its movement. Obviously this is not good enough either.

1 [Originally published in JP, 1970, 34, 197-209]

2 This paper was presented as the luncheon address at the Winter Review Meeting of the Institute for Parapsychology on January 3, 1970. 
But do we need to make a choice between one extreme and the other? Of course not. My basic argument to you today is that we need, for good description, multiple levels of analysis from the largest possible units to the smallest and most precise, and that somehow these analyses must be welded together so that they show the time sequences within each level and between levels. This thinking has led me to my current research, an attempt with Laurence Lewis to study the individual psi experience; and my talk today will present the line of reasoning, sketch out the project, and tell you of the high hopes that we hold for it now - the kind of unrealistically high hopes that we can enjoy in the planning stage before the data come in, but that are all too likely to be cast down as soon as we have results to study.

Let me continue with the basic argument. Any research project ordinarily compromises with the ideal multilevel description by choosing some convenient time sample and treating all the events that take place within it as if they were a unit. Sometimes we choose a big sample, like someone's childhood-those complex events of many years which can be (inadequately) summarized in a single word, "deprived" or "happy." Or we may choose a smaller sample like a child's learning to read or an adult's decision on how to vote in an election or a psychic's period of vacillation between his first psychic experience and his decision to develop his psi ability. Or we may select a still smaller sample, like the token-object sittings that Mrs. Garrett held here. Or a still smaller unit like the score of a subject on a single ESP run. In one sense it is fair to say that the bigger the sample, the better and more meaningful it is because it encompasses a reasonably large span of events; but on the other hand the bigger the sample, the worse it is, the less accurate, because it will blur separable processes into a single description. To put it briefly, we must choose breadth or accuracy or some fuzzy compromise.

Where does this leave us if as scientists we want to describe the psi process (or any other psychological function)? In a bad spot, because no single project will give us what we need. We must have information from varied approaches which give supplementary data.

I think, for example, that we need something we have never had: a sociology of psi, an analysis of why some cultures or some periods of history seem to produce more massive ESP or PK phenomena and more gifted sensitives than do others. But I also think we need the smaller scale study of individual lives. This could relate a person's shifting psi sensitivity-sometimes strong and sometimes weak or perhaps absent-to his changes in needs and moods, his distress and contentment and loving, his varying openness to the world around him, and also to the other persons with whom he is in contact and to their shifts in needs and sensitivity and response to him. But besides these sociological and life history approaches, I think we need research on smaller units, like a person's ESP or PK scores in a single session of a half-hour or hour (research in which I have a vested interest because I have been doing it for so many years). Even though today my emphasis will be on the virtues of the purest and smallest unit possible, the single response, you should not take this as derogating the other kinds of study. I am urging supplementation, not substitution.

Suppose for the sake of argument that we opt, as I am currently doing, for accuracy rather than breadth. Is it appropriate to choose as our unit the score of a singe ESP run? No, it is not. Both Dr. Rhine and Mrs. Rhine have separately told us that if we look closely at a single run we will find in it a combination of psi-hitting and psi-missing. To state that even a high score like a 12 shows good per- 
formance throughout the run would be as bad a mistake-as silly, really-as saying that in Durham the mean annual temperature is 60 degrees and therefore ovbiously the Durham climate is moderately cool. Perhaps it is, overall; but to describe it without blur you must show how it ranges in irregular cycles from subfreezing to uncomfortably hot.

Then how small a time span do we need to capture the psi unit? Should it be the interval between one response and the next? No, this also is too long, because it can include so many hesitations, blank pauses, rejections of tentative decisions. What we must ask is, in effect: How long does the actual psi experience last? Should our units of measurement be milliseconds, or seconds, or very much longer? I wish we knew; but as things lamentably stand on the third day of 1970, we have neither the data that permit a firm statement nor the theory that would let us set up a good guess.

Where laboratory data and theory are lacking, our best source of information is likely to be naturalistic observation. I therefore have turned to the reports of those who collected spontaneous cases for us-from Frederick Myers to Louisa Rhine-for a first answer to this question of how long an ESP experience is likely to last.

The records give no clear directive. (This in itself may be our first useful item of information, an important warning that any single, simple answer is likely to fall far short of the truth.) Two major difficulties confront us in the case collections. The first is that so many of the best cases are dreams. This is no help when you are looking for time estimates, because even though reports from dream laboratories indicate that a dream is likely to last as long as would a corresponding experience in waking life, it still seems risky to assume a one-to-one relation. In this current reading I have therefore skipped the many dream reports (though perhaps it would be wiser to take them as a model and plan to put all our subjects to sleep before collecting data).

The second major difficulty is that so many of the waking cases describe two kinds of events. One is the psi information. The other is a changed state of consciousness: perhaps a feeling of being out of the body, or a sort of double vision which mysteriously includes everyday reality and the disparate psi hallucination, or an intense anxiety that continues for hours or recurs over several days. Should this changed state be considered an intrinsic part of the psychic experience? If it is, it implies that psi can last for a very long time. But we must hesitate before deciding, because within the prolonged period of altered consciousness there are likely to be only a few bits of information that seem psychic-what Ehrenwald calls "tracer elements." Thus, if there is a forty-minute period of unusual, intense misery with the feeling, "Something is the matter with John," we do not know if the psychic information itself is emerging during that entire period. Maybe it is; it might be coming through repeatedly in a redundant message. But another possibility is that the prolonged altered state represents the consequence of opening the gates for a short psychic message; it and the message may be the results of the same cause. And still a third possibility is that the long conscious state was caused by the psychic message but was not in itsef psychic. We do not yet know how to interpret it; I was interested but dared not use it.

What I looked for, to get a clearer answer, was case reports which seemd to describe specific psychic information and also to indicate upper and lower limits for the period in which specifics came through. Lower limits were easy to find. Again and again percipients said, "In a flash..." or "The picture 
flashed into my mind," or "Suddenly I heard ..." The smallest describable unit of psychological time seemed to set the lower limit for the psi experience. Since information on short-term memory suggests that 10 to 100 milliseconds is about how long it takes to process an item of visual information, we can infer that the same time range approximates the flash of a single psi impression.

But what is the upper limit? Are there longer psi experiences? Here is a case from an early report by Mrs. Rhine which sounds as if it lasted considerably longer. The woman who describes it writes:

The Sunday School was giving the children ... a hay ride... The superintendent was driving the truck and I had no uneasiness about their safety. Late that afternoon, about the time for the picnickers to be getting home, a neighbor dropped in and we sat talking on the screened porch. While she was talking my mind drifted off and I was seeing the truckload of children coming upthe road a mile or more away. I saw them clearly, a noisy crowd on a hay ride and the older ones sitting with their legs hanging over the side. Suddenly from the other direction a car came down the road. Just as it reached the truck it swerved in and scraped the edge clean of children. It was a horror of confusion with arms and legs in all directions. The picture snapped off suddenly then.

She goes on to write that her own child came home unhurt; that she then learned the accident had happened as she saw it, with several children injured, at just about the time of her vision; and that it had taken place so far away that she did not hear the sirens of the ambulances when they came to take the children to a hospital. It seems to have the ring of an authentic psychic experience; I found it impressive that she did not claim to know her own child was safe or to see which children were hurt. If we try to judge how long it could have taken her, while a neighbor was speaking, to see the first normal scene, then the car first going straight and later swerving, the catastrophe, and a part of its aftermath, it is clear that we cannot estimate with much assurance. Perhaps two seconds would be a minimum approximation and 20 to 30 seconds a more reasonable one.

This case seemed the longest of those I read in two books and over a dozen articles by Mrs. Rhine, though perhaps her case of a fruit vendor on 124th Street would be a competitor if its details were clearer. Back in the leisurely Victorian or Edwardian period, psi seemed to last longer; and if you read cases from recent decades and then from the decades about the turn of the century, you may agree with me that a sociology of psi would be useful to explain the differences. Take, for example, this story from the England of 1892, reported by Sir Joseph Barnby after a visit to the home of Lord and Lady Radnor:

The Radnors had as house guest a woman designated as Miss A., who had had many psychic experiences, some of them induced by crystal-gazing. One evening Miss A. looked into a crystal ball and saw there a room which she described as "a kind of London dining room" with large squares of black and white marble on the floor. From this, and her later descriptions of people in the room, Lady Radnor thought she could identify Lord and Lady L. and their dining room in a house outside of London (which was, as Miss A. had said, "a kind of London dining room." Miss A. went on to say, "Here are a number of people coming into the room. Why, they're smelling their chairs!" then continued until it became clear to her listeners and to her that they were not smelling, but kneeling before their chairs for family prayers. 
She described the ceremony and the man conducting it, then said, "A lady just behind him rises from her knees and speaks to him. He puts her aside with a wave of the hand, and continues his reading." The woman who made the unconventional interruption seemed from the description to be Lady L. The next evening, when Lord and Lady L. visited the Radnors, Lady Radnor (in the presence of Sir Joseph Barby, who had heard about the last evening's crystal gazing) learned from Lord $L$. that the preceding evening at the time of the crystal vision, the L.'s had been at family prayers in the room that Miss A. described, that Lady L. had risen from her knees and spoken to him and that he had put her aside with a wave of his hand. The account sounds as if Miss A. had been observing in the crystal distant but contemporaneous events as they occurred and as if her psi experience continued with veridical detail for a substantial period of time, of the order of ten minutes.

Even in Victorian England, such a long psychic description was uncommon. Others I have found all came, as did this one, from individuals who had had many psychic experiences. However, in most cases the fresh items seem studded among generalized descriptions; they sound as if there was a long altered state of consciousness during which a few new details occasionally appeared. Perhaps our best guess about the duration of psi experience is that the distribution of times is J-shaped; that frequency is highest in the shortest unit of psychological time, so that almost all occur "in a flash"; but that they trail off into longer periods, perhaps extending in some few extreme cases to several minutes, or conceivably even longer.

This quick survey suggests several useful possibilities for research, and I will propose three. One is to work with the best, longest instances of psi because they offer more time to examine their concomitants. This would entail a two-stage project. The first step would be to find and encourage those who are capable of experiencing long psi interludes; the second to examine the conveniently long times when they occur. (I will return to this tempting method later and examine some of its problems.) A second kind of research would attempt to find those distinctive altered states on which psi is likely to be embedded. This also would be a two-part project, aimed at finding the distinguishing features both of the altered state and of the psi itself. A third line of research would be to take psi as it ordinarily comes, that is, quickly. We would need to use such short time-samples that we are, as nearly as possible, working with the pure period of the psi impression undiluted by the nonpsi states that precede and follow it. This probably, as I mentioned, means working with time units of the order of 10 to 100 milliseconds (though a possibility we must consider is that the shortest psychic event is so different from the shortest visual event that longer or even shorter periods are needed for registration and response).

Research with such short periods requires sophisticated instrumentation of the kind that only rather recently has been used in parapsychology, by such innovators as Tart or Ullman. By now, however, many others, like Kahn in Georgia and Van de Castle in Virginia, have moved in the same direction. I will tell you soon how I am beginning to probe along these lines. But first it is necessary to make a digression and describe still another difficulty that impedes our way. It will be a long digression, because the difficulty is compounded of three related but separable parts: that subjects can ordinarily neither be sure of recognizing psi when it appears nor of controlling its appearance; that psi information is often incomplete or misdirected (as in psi-missing or other displacement effects); and that there is no completely reliable way as yet of distinguishing for any one success whether it is due to ESP (or PK) or is only a matter of chance. 
This last is a problem that all of us in parapsychology have lived with for a long time: identifying psi when it appears and distinguishing it from nonpsi. It is like the problems that physicists have in spotting a new particle from the tracks it leaves in a cloud chamber; it takes a high level of expertise to distinguish one track from another. It is a pressing problem in many parts of psychology too. Perception is often hard to distinguish from guessing guided by response bias; empathy can be confounded with a person's own natural mode of response. In parapsychology we put the difficulty this way: When is a particular hit an ESP hit instead of an accidental coincidence?

The simplest way of getting around the problem is for the experimenter to choose as the correct response one which is so distinctive that it would almost never appear by accident, one name or word or object out of the multitude of possible ones. If the subject identifies this unique item, it is a success; if not, it is a failure. The method may be a good one when the subject's ESP ability is strong. But as we all know too well, it is inefficient-not a good method-for studying run-of-the-mill, weak ESP ability. Most subjects would have so many hundred failures before a single success that both they and the experimenter would grow discouraged; the research would probably stop because of boredom before it was well begun. The method we use instead in parapsychology-and in signal detection research, and in running rats through mazes-is to specify as correct one out of some small number of possible responses. Even if a subject is functioning at or near the chance level he will have some successes this way; both he and the experimenter will feel more cheerful; and there is more likelihood of the project's being completed without dropouts.

Obviously the trouble with this useful approach is that it demands a large sample of responses. Because chance expectation of success is high, we need to average many trials to find what has been happening. We end up, in laboratory slang, with dirty data. Even when the overall score seems clearly better than chance, with ESP cards we must assume that about one hit in five tries was only a chance hit. If a preselected brilliant subject makes the phenomenal average of 9 hits per run over 20 runs, more than half of those hits should conservatively be assigned to coincidence rather than psi; and we do not know which are which. The run gives a blur of psi-hitting and psi-missing and perhaps displacement too; and it gives a blur of psi hits and chance hits even when hits and misses are segregated.

What can we do about it? My first recommendation is simple; we should use it to help build a model for psi. Consider again the hypothetical brilliant subject who was selected for special examination because of his prior good scores and who then for 20 runs averaged 9 hits per run. We infer that about 4 out of every 25 calls, on average, showed effective psi. But suppose that instead of ESP cards, our targets had been playing cards, or words from the dictionary, like Carington's targets. Would we expect the subject to average 4 extra hits out of 25 calls with these long-shot targets? Of course not. Even with gifted subjects, the number of extrachance hits changes as the odds change. This tells us something. Psi is not a simple on-off process which gives full information whenever it appears. To study it well, we must look for gating and decision mechanisms and for cases where it is part right, part wrong (displacement effects, or the near misses that Fisk found with his clock-card technique, or psi-missing, which we may think of as 180-degree displacement). 
A second thing we can do when we try to clean up the data is a kind of microanalysis of scoring patterns within the run. We may find, for example, that the first segment (the first five calls) includes the whole surplus of hits; and in the rare cases where this occurs we can infer that the psi hits are those of the first segment. Or we may find that the surplus comes from hits on circles, as Fisk found in his research with erotic symbols. Or that it appears on the second or third target of a repetitive sequence, or only for the third item in an ABA type of sequence (like square, star, square; or circle, plus, circle). I do not need to remind you that Gaither Pratt found that this approach is usable; some subjects sometimes seem to function in almost as clear-cut a way as this, making it possible to segregate what seem to be their psi successes from what seem to be their chance successes. But one person will vary from time to time in his success-failure patterns (as Gaither Pratt also found), and of course subjects vary from each other. Long-term consistent effects of this clear-cut sort are too infrequent to help us much. Though this within-run microanalysis is interesting in itself, it does not seem likely to be an efficient technique for studying pure cases of psi.

A third course is to find gifted subjects with whom we can use longer odds so that they will give us cleaner data. This is a counsel of perfection: the easiest possible advice to give and the hardest to follow. One advantage is clear; even with long odds, such gifted subjects would have enough successes to stay hopeful. We could clean up the research without washing it out. Another possible advantage is that, by inference from the case material mentioned earlier, we could reasonably hope that gifted subjects would produce individual psi experiences which would last longer than the usual flash; and this would give us more time to explore their correlates.

But the disadvantages of restricting our research to gifted subjects are clear too. Such subjects are hard to find; and each is so different from the others (as even we nongifted folk are from each other) that when you work with a second one, your experience with the first is of little use to you. With each, you need a long preliminary project to identify when he is entering his own psi-hitting phase. By the time a gifted subject has been tested enough to establish that he is gifted and to show how he typically functions, he is likely to be so bored with the testing methods that he demands new methods to sustain his interest, and the new methods require a fresh preliminary investigation. This can grow discouraging.

One further possibility, a variant of the last one, is that instead of merely trying to find gifted subjects, we try to develop them. This is what Lewis and I are now attempting, even though training subjects in the laboratory has been tried often before with limited or no success. It may be that we are following a will-o'-the-wisp. At least it has the advantage that we can choose subjects-or let potential subjects choose us as experimenters-who are tolerant of laboratory procedure and will give a fairly long-term commitment to it. The big question is: Will the training procedure work? We have tried to hedge our bets by combining with the training, as part of the research design, an intensive study of each response. This makes it a kind of double- or triple-barreled project which examines the individual response and the accompanying events in which it is embedded and also tries to encourage the mental state which is conducive to psi. Let me take the last few minutes of this talk to tell you about it.

It starts from the work that Kamiya has been doing on alpha feedback. You probably know that when brain waves are analyzed on an EEG record, certain fairly slow, regular waves are for convenience 
given the name "alpha." They are associated with drifting thoughts or a kind of relaxed, detached attention; they disappear in sleep and are inhibited by concentrated thought or interesting stimuli. Although these and others, like beta and theta waves, are presumably associated with mental functions, Kamiya was the first to show that we could become aware of when we are "in alpha" (that is, when our EEG shows clearly the distinctive alpha pattern). Kamiya's method, an elegantly simple one, was to signal a subject and ask, "Now?" The subject had to say either yes or no without the foggiest notion of what he was guessing about. If he had been in alpha and said yes, Kamiya told him that he was right; but if he had said yes when he was not in alpha, Kamiya told him he was wrong. Many subjects learned very quickly, with extraordinary success, to say yes and no at the right times. They had become conscious of a brain state which, until then, they had never identified. Later work showed that along with identifying this state, they had gained substantial control over it. They could put themselves in alpha voluntarily and could eliminate it when they chose.

This is fascinating in itself, quite aside from its implications for ESP. The alpha state is usually experienced as pleasantly calm, and I have even had one subject who thanked me enthusiastically for having learned it. She was a graduate student and had recently become so upset with one of ther textbooks that each time she opened it she found herself too anxious to understand what she was reading. After the alpha training she deliberately put herself into the alpha state before studying her next assignment in this text and found herself calm enough to read and understand it. Alpha training has seriously been suggested as a substitute for tranquilizers.

Meanwhile, in other laboratories besides Kamiya's, the same kind of feedback training has been used successfully for other body functions. Animals were trained by immediate rewards to speed up their heart beats or slow them down; humans have learned to change their skin temperature; there is a long list of previously unconscious functions which have been bought under voluntary control. This makes the method seem a natural for psi training, where the problem of establishing voluntary control of an unconscious function has given us such difficulty. And what we are trying to do in our own research-which, as I said, is just beginning, so that it's too early to tell you or even to guess ourselves if it's going to work-is first to train subjects in alpha, because we know this can be done. Then, after they have learned to identify and control alpha, we hope (in the classic phrase) that they will have "learned to learn" and we will set them to do their next learning with the indispensable help of Dr. Helmut Schmidt's machine; to try to identify psi and control it, just as they have learned alpha identification and control.

You probably see how this ties in with the general topic of the talk: studying individual psi experiences and their relation to other events. The machine that we use for recording gives a continuous record that can be divided into very small time-samples of the right order of magnitude for us. While the subjects are making their ESP calls, their brain waves are being recorded on the same tape as the ESP hit or miss. We can therefore analyze the records for general brain state over a long time-span like five minutes and can also analyze them for the particular state preceding and during the ESP call. One thing we will do, of course, is see if we replicate Honorton's finding that periods with a higher proportion of alpha give more ESP hits. We will also look at whether alpha is present during the individual psi hit or miss, and if not, whether any other distinctive wave pattern is present then. At best, we can teach identification and control of psi and find how it relates to the accompanying states in which it is embedded; 
and from the latter information we will be able to distinguish psi hits from chance hits. At second best, we will turn up something unexpected. At a weak third best, we will have such clear null results that we will keep other experimenters from wasting time on the same useless project. In any event, we'll have been in there, trying.

\section{Etudier Les Expériences Psi Individuelles}

RESUME : Pour comprendre le psi, nous devons l'étudier à de multiples niveaux d'analyse. Nous avons besoin d'une sociologie du psi, examinant les patterns de ses manifestations dans différentes cultures et différents groupes sociaux; des données biographiques de manière à comprendre les causes pour les changements de capacité psi individuelle; recherche sur les conditions qui affectent l'ESP et la PK dans de courtes périodes telles qu'une unique session expérimentale ; et nous avons également besoin d'un examen minutieux des expériences psi individuelles. Cette dernière voie est particulièrement difficile pour plusieurs raisons : (1) La durée des expériences individuelles est inconnue (une revue de cas spontanés suggère qu'elles peuvent durer le temps d'un flash, soit un dixième ou centième de seconde, ou peut continuer pour plusieurs minutes) ; (2) tout succès à une expérience d'ESP pourrait être dû à la chance, non au psi ; (3) le psi donne souvent des informations imparfaites (soit partiellement correctes ou systématiquement mal orientées) ; et (4) le psi n'est pas habituellement sous le contrôle conscient.

Nous examinons des suggestions pour faire face à ces difficultés. Une expérimentation en cours est décrite dans laquelle les modifications d'EEG sont étudiées en fonction des expériences psi individuelles et où sont réalisés, en même temps, des essais pour apprendre aux sujets à identifier et contrôler les succès psi.

\section{Zur Untersuchung Individueller Psi-Erfahrungen}

ZUSAMMENFASSUNG: Um Psi zu verstehen, müssen wir es auf mehreren Untersuchungsebenen analysieren. Wir brauchen eine Soziologie von Psi, die seine Muster in verschiedenen Kulturen und sozialen Gruppen untersucht; lebensgeschichtliche Daten, damit wir Ursachen für Veränderungen in der Psi-Fähigkeit eines Individuums finden können; Erforschung der Bedingungen, die ASW und PK in kurzen Zeiträumen-wie in einer einzelnen experimentellen Sitzung-beeinflussen; und wir benötigen auch eine sorgfältige Untersuchung des individuellen Psi-Erlebens. Letzteres ist aus mehreren Gründen besonders schwierig: (1) Die Dauer der individuellen Erfahrung ist unbekannt (eine Auswertung der Spontanberichte deutet darauf hin, dass sie, für den kürzesten berichtbaren Einfall von vielleicht einer Zehntelsekunde oder Hundertstelsekunde, bis zu mehrere Minuten andauern kann); (2) jeder einzelne Treffer in einem ASW-Experiment kann zufällig und nicht durch PSI verursacht worden sein; (3) Psi liefert oft unvollkommene Informationen (nur teilweise korrekte oder in systematisch fehlgeleiteter Information); und (4) Psi entzieht sich normalerweise der bewussten Kontrolle.

Vorschläge zur Bewältigung dieser Schwierigkeiten werden geprüft. Ein in laufendes Experiment wird beschrieben, das EEG-Änderungen im Zusammenhang mit der individuellen Psi-Erfahrung untersucht und gleichzeitig versucht, den Probanden beizubringen, den Psi-Erfolg zu identifizieren und zu kontrollieren. 


\section{El Estudio de las Experiencias Individuales de Psi}

RESUMEN: Para entender a los fenómenos psi, debemos estudiarlos en varios niveles de análisis. Necesitamos una sociología del psi, examinando sus patrones en diferentes culturas y grupos sociales; datos de la cronología de la vida para que podamos encontrar las causas de los cambios en la capacidad psi de un individuo; investigar las condiciones que afectan a la PES y la PK en períodos cortos como una sesión experimental única; y también necesitamos un examen cuidadoso de la experiencia individual de psi. Lo último es particularmente difícil por varias razones: (1) La duración de la experiencia individual es desconocida (una revisión de casos espontáneos sugiere que pueden durar el momento informable más breve, quizás una décima o centésima de segundo, o pueden continuar por varios minutos); (2) los aciertos en un experimento PES pueden ser debidos al azar, no a psi; (3) psi a menudo da información imperfecta (sólo parcialmente correcta o sistemáticamente mal dirigida); y (4) psi no está normalmente bajo control consciente.

Se examinan sugerencias para hacer frente a estas dificultades. Se describe un experimento en curso que investiga los cambios de EEG relacionados con la experiencia individual de psi y, al mismo tiempo, intenta enseñar a los sujetos a identificar y controlar los aciertos psi. 